\title{
Clinical characteristics of survivors and non- survivors, medical and non-medical staff members with 2019-nCoV pneumonia in Wuhan, China: a descriptive study
}

Jiaxun Hu

Changzheng Hospital

You Lv

Changzheng Hospital

Ying Xu

Hankou hospital

Yushan Miao

Changzheng Hospital

\section{Wei Wang}

Changzheng Hospital

\section{Wenqing Le}

Hankou hospital

Hao Tang ( $\nabla$ tanghao_0921@126.com )

Changzheng Hospital https://orcid.org/0000-0003-1536-1944

\section{Research}

Keywords: 2019-nCoV; Clinical characteristics; Mortality; comorbidity; Survivors; Non-survivors; Medical Staff

Posted Date: April 7th, 2020

DOl: https://doi.org/10.21203/rs.3.rs-20714/v1

License: (a) This work is licensed under a Creative Commons Attribution 4.0 International License. Read Full License 


\section{Abstract}

Objectives: In December 2019凶the 2019 novel coronavirus ( 2019-nCoV ) emerged in Wuhan, China, leading to a cluster of severe pneumonia cases. Medical staff members on the front line were also infected. We compared the epidemiology, clinical characteristics, and treatment measures of survivors and non-survivors and the different clinical outcomes of medical staff members and non-medical members of the community infected with 2019-nCoV.

Methods: We included 81 patients with adult 2019-nCoV in Hankou Hospital from mid-January to midFebruary 2020 in this single-center retrospective study. Data were compared between survivors and nonsurvivors and between medical staff members and non-medical individuals.

Results: All 38 medical staff members were infected by patients while working. Only 2 (2.5\%) non-medical individuals had a clear history of exposure to 2019 -nCoV patients. The median age was 49 years (interquartile range [IQR], 35-59; range, 23-89 years), and 42 (51.9\%) were women. We found that the median age,comorbidity, and some laboratory outcomes(lymphocyte count, urea nitrogen, aspartate aminotransferase, lactate dehydrogenase, etc.) differed significantly between survivors and non-survivors. There were also significant differences in the time from onset to admission, disease classification, comorbidity, and prognosis between medical staff members and non-medical individuals. All medical staff members were cured, while 13 (30.2\%) non-medical individuals died.

Conclusions: Older males with comorbidities are more likely to be affected by 2019-nCoV. Significant changes in some laboratory markers may indicate a poor prognosis. Medical staff members may have had better prognoses due to fewer comorbidities and better medical compliance. Key words: 2019-nCoV; Clinical characteristics; Mortality; comorbidity; Survivors; Non-survivors; Medical Staff

\section{Introduction}

Since December 2019, several cases of unexplained pneumonia were discovered in hospitals in Wuhan, Hubei province, China. These cases were later confirmed to be novel coronavirus-infected pneumonia, caused by a new type of coronavirus (2019-nCoV) [1-3]. This 2019-nCoV pneumonia has now been included among the Class B infectious diseases stipulated in the Law of the People's Republic of China on the Prevention and Control of Infectious Diseases and has been managed according to the Class A guidelines. The characteristics of 2019-nCoV include strong infectivity, a long incubation period, complex transmission channels, and diverse clinical characteristics [3]. Most patients have mild fever, a nonproductive cough, myalgia, dyspnea, or fatigue at the onset of the disease. In severe cases, infection can lead to pneumonia, acute respiratory distress syndrome, multiple organ failure, and even death. As of March 31, 2020, more than 82,000 2019-nCoV pneumonia cases had been confirmed in China, and more than 700,000 cases had been reported in other countries.

Vaccination is the most effective strategy to prevent and control virus infection. However, there is no vaccine specifically for 2019-nCoV. Apart from antiviral drugs such as lopinavir and ritonavir, the main 
clinical treatment is still symptomatic and supportive treatment.

We aim to describe the epidemiological, demographic, and clinical data of patients with 2019-nCoV infection and compare clinical characteristics between survivors and non-survivors and between medical staff members and non-medical members of the community. We hope that our findings will provide a scientific basis for further prevention and treatment of 2019-nCoV pneumonia.

\section{Methods}

\section{Study design and participants}

We recruited 81 patients admitted to Hankou Hospital in Wuhan from mid-January to mid-February 2020 in this single-center, retrospective study. The medical team of Changzheng Hospital, which supports Hankou Hospital, has been assigned by the government to provide treatments for $2019 \mathrm{nCoV}$ pneumonia. All included patients were diagnosed with 2019-nCoV pneumonia according to interim guidance from the World Health Organization, and patients with inadequate clinical information were excluded. The 81 admitted patients included 38 medical staff members infected with 2019-nCoV while providing first-line treatments. We collected all available electronic medical records, nursing records, and patient data for the analysis. The study was approved by the ethics committees of Hankou Hospital (HKYY-2020-022) and Changzheng Hospital (2020SL009), and written informed consent was obtained from all of the patients or their next of kin.

\section{Data collection}

Real-time reverse transcriptase-polymerase chain reaction (RT-PCR) confirmed that the patients included in this study were infected with 2019-nCoV. We reviewed the demographic, epidemiological, laboratory, radiological, treatment, and prognosis data from the patients' medical records and followed their clinical outcomes until Feb 27, 2020. The collected data included name, gender, age, work, time of onset, time of treatment, time of hospitalization, exposure history, comorbidities (hypertension, coronary heart disease, diabetes, tumor, other chronic diseases), symptoms (fever, cough, fatigue, dyspnea, headache, sore throat, diarrhea), laboratory indicators, chest computed tomography (CT) scans, medication (antiviral drugs, glucocorticoids, immunoglobulin, antibiotics), disease classification, and prognosis. Three physicians checked all the data carefully (HJX, MYS and WKC).

\section{Outcomes}

We statistically analysed epidemiological data (i.e., living near or engaged in short- or long-term work near the Huanan seafood market, where the outbreak likely originated; history of patient exposure), demographics, symptoms at admission, comorbidities, infection of other respiratory pathogens, laboratory indicators, results of chest CT scans, medication treatment, disease classification, and prognosis.

\section{Statistical analysis}


Normally distributed continuous variables were presented as the mean (standard deviation [SD]). If not normally distributed, they were expressed as the median (interquartile range [IQR]). Categorical variables were expressed as the number (\%). The two-sample $t$ test was used to assess the differences between survivors and non-survivors and between medical staff members and non-medical individuals if the data of continuous variables was parametric; if not, the Wilcoxon rank-sum test was used. Fisher's exact test was used for categorical variables. We will double check the laboratory indicators. SPSS (version 26.0) was utilized for all analyses.

\section{Results}

As of February 15, 2020, 81 patients diagnosed with 2019-nCoV pneumonia at Hankou Hospital were included in the study. All of them were residents of Wuhan City, including the 38 medical staff members infected by patients while working. Among the 38 medical staff members, 31 were from Hankou Hospital and 7 were transferred from other hospitals. Forty-three non-medical individuals did not have a clear history of direct exposure to the Huanan Seafood Market, but 2 (2.5\%) had been exposed to confirmed or highly suspected 2019-nCoV infections. The median age of all patients was 49 years (IQR, 35-59; range, 23-89 years), and 42 (51.9\%) were women. There were no children or adolescents among the included patients. The median time from onset to hospital admission or medication was 5 days (IQR, 3-9). Almost all patients were admitted one day after their chest CT results came back positive, and they began receiving medication once admitted. Among the included patients, 38 (46.9\%) had chronic diseases, including hypertension (16 [19.8\%]), diabetes (6 [7.4\%]), coronary heart disease (7 [8.6\%]), tumor (3 [3.7\%]), chronic obstructive pulmonary disease (3 [3.7\%]), and other chronic diseases (25 [30.9\%]) such as chronic gastritis, hypothyroidism, sequelae of cerebral infarction, and myasthenia gravis. The results of all pharynx swabs for influenza $A$ and $B$ were negative. The most common symptoms at onset were fever (85.2\%), cough (54.3\%), and fatigue (33.3\%). Other symptoms included dyspnea (14.8\%), sore throat $(6.2 \%)$, headache $(4.9 \%)$, and diarrhea $(4.9 \%)$. All patients were diagnosed with unilateral or bilateral typical changes in a chest $\mathrm{CT}$, including patch and cloud-like infiltration shadows or ground glass opacity. In the routine blood test performed upon admission, the leucocyte count was lower than normal in 23 (28.4\%) patients, and the leukomonocyte count was lower than normal in 48 (59.3\%). The platelet count was lower than normal in $14(17.3 \%)$ cases, while the C-reactive protein level was higher than normal in 52 (67.9\%). The median C-reactive protein level was $16.12 \mathrm{mg} / \mathrm{L}(\mathrm{IQR}, 6.1-42.8 \mathrm{mg} / \mathrm{L} ;$ Normal 0-6 mg/L), and the median procalcitonin level was $0.062 \mathrm{ng} / \mathrm{ml}$ (IQR, 0.042-0.118; Normal 0-0.05 ng/ml), reflecting the inflammatory state of the body (Table 1 and Fig. 1). Twenty-four of the 81 patients were admitted to intensive care units (ICU); of these, 13 died and 11 were cured. The ICU mortality rate was $54 \%$. Organ function impairment occurred in a small number of patients, including $14(17.2 \%)$ patients with acute respiratory distress syndrome, $2(2.5 \%)$ patients with acute kidney injury, $9(11.1 \%)$ patients with heart injury, and $22(27.2 \%)$ patients with abnormal liver function. In all, 77 (95\%) patients received antiviral therapy, including oseltamivir (76.5\%), ritonavir (27.2\%), lopinavir/ritonavir (23.5\%), umifenovir (7.4\%), and ribavirin (2.4\%). Eighty (98.8\%) patients accepted antimicrobials, including moxifloxacin, cefoperazone sodium and sulbactam sodium, azithromycin, and cephalosporin. Fifty-three (65.4\%) 
patients accepted glucocorticoid, and 72 (88.9\%) accepted immunoglobulin. Thirty-six (44.4\%) patients received oxygen support due to hypoxemia. 
Table 1

Demographics, baseline characteristics, symptoms, comorbidities, laboratory examination and treatments of patients with 2019-nCoV pneumonia. Data are median (IQR), $\mathrm{n}(\%)$, or $\mathrm{n} / \mathrm{N}$ (\%), where $\mathrm{N}$ is the total number of patients with available data. $\mathrm{p}$ values comparing survivors and non-survivors are from $\chi^{2}$ test, Fisher's exact test, or Mann-Whitney U test. 2019-nCoV $=2019$ novel coronavirus.

\begin{tabular}{|c|c|c|c|c|}
\hline & Total $(\mathrm{n}=\mathbf{8 1})$ & survivors $(n=68)$ & $\begin{array}{l}\text { Non-survivors( } \mathrm{n}= \\
13)\end{array}$ & $\begin{array}{l}\mathrm{P} \\
\text { value }\end{array}$ \\
\hline Age(median [IQR] y) & $49(35-59)$ & $42(33-54)$ & $69(60-79)$ & $\begin{array}{l}< \\
0.001\end{array}$ \\
\hline Sex & प्रा & स्प & प्रा & 0.292 \\
\hline Male & $39(48.1 \%)$ & $31(45.6 \%)$ & $8(61.5 \%)$ & 吅 \\
\hline female & $42(51.9 \%)$ & $37(54.4 \%)$ & $5(38.5 \%)$ & 吅 \\
\hline $\begin{array}{l}\text { Time from onset to CT } \\
\text { positive } \\
\text { (median [IQR], d) }\end{array}$ & $4(2-8)$ & $4(2-9)$ & $5(2-6)$ & 0.430 \\
\hline $\begin{array}{l}\text { Time from onset to } \\
\text { admission } \\
\text { (median [IQR], d) }\end{array}$ & $5(3-9)$ & $5(3-10)$ & $6(3-7)$ & 0.430 \\
\hline $\begin{array}{l}\text { Time from onset to } \\
\text { medication } \\
\text { (median [IQR], d) }\end{array}$ & $5(3-9)$ & $5(3-10)$ & $6(3-7)$ & 0.430 \\
\hline Comorbidity & $38(46.9 \%)$ & $27(39.7 \%)$ & $11(84.6 \%)$ & 0.003 \\
\hline Hypertension & $16(19.8 \%)$ & $10(14.7 \%)$ & $6(46.2 \%)$ & 0.018 \\
\hline Diabetes & $6(7.4 \%)$ & $2(2.9 \%)$ & $4(30.8 \%)$ & 0.005 \\
\hline Coronary heart disease & $7(8.6 \%)$ & $2(2.9 \%)$ & $5(38.5 \%)$ & 0.001 \\
\hline Tumor & $3(3.7 \%)$ & $3(4.4 \%)$ & $0(0 \%)$ & 1.000 \\
\hline COPD & $3(3.7 \%)$ & $1(1.5 \%)$ & $2(15.4 \%)$ & 0.066 \\
\hline Other & $25(30.9 \%)$ & $18(26.5 \%)$ & $7(53.8 \%)$ & 0.097 \\
\hline $\operatorname{Fever}\left(\geq 37.3^{\circ} \mathrm{C}\right)$ & $69(85.2 \%)$ & $56(82.4 \%)$ & $13(100 \%)$ & 0.198 \\
\hline Cough & $44(54.3 \%)$ & $38(55.9 \%)$ & $6(46.2 \%)$ & 0.519 \\
\hline Fatigue & $27(33.3 \%)$ & $24(35.3 \%)$ & $3(23.1 \%)$ & 0.528 \\
\hline Dyspnea & $12(14.8 \%)$ & $9(13.2 \%)$ & $3(23.1 \%)$ & 0.398 \\
\hline Headache & $4(4.9 \%)$ & $4(5.9 \%)$ & $0(0 \%)$ & 1.000 \\
\hline Sore throat & $5(6.2 \%)$ & $5(7.4 \%)$ & $0(0 \%)$ & 0.587 \\
\hline
\end{tabular}




\begin{tabular}{|c|c|c|c|c|}
\hline & Total(n = 81) & survivors(n = 68) & $\begin{array}{l}\text { Non-survivors }(n= \\
\text { 13) }\end{array}$ & $\begin{array}{l}P \\
\text { value }\end{array}$ \\
\hline Diarrhea & $4(4.9 \%)$ & $3(4.4 \%)$ & $1(7.7 \%)$ & 0.511 \\
\hline \multicolumn{5}{|l|}{ Blood routine (median [IQR]) } \\
\hline $\begin{array}{l}\text { White blood cell, } 10^{9} / \mathrm{L} \\
\text { (Normal 3.5-9.5*10\%) }\end{array}$ & $4.3(3.3-5.8)$ & $4.3(3.2-5.3)$ & $5.8(4.3-7.5)$ & 0.063 \\
\hline$<3.5$ & $23(28.4 \%)$ & $20(29.4 \%)$ & $3(23.1 \%)$ & 0.749 \\
\hline $3.5-9.5$ & $55(67.9 \%)$ & $46(67.6 \%)$ & $9(69.2 \%)$ & 1.000 \\
\hline$>9.5$ & $3(3.7 \%)$ & $2(2.9 \%)$ & $1(7.7 \%)$ & 0.413 \\
\hline $\begin{array}{l}\text { Leukomonocyte count, } \\
10^{9} / \mathrm{L} \\
\left.\text { (Normal } 1.1-3.2 * 10^{9} / \mathrm{L}\right)\end{array}$ & $0.9(0.6-1.3)$ & $1(0.7-1.4)$ & $0.5(0.3-0.8)$ & 0.001 \\
\hline$<1.1$ & $48(59.3 \%)$ & $36(52.9 \%)$ & $12(92.3 \%)$ & 0.008 \\
\hline $\begin{array}{l}\text { Neutrophile count, } 10^{9} / \mathrm{L} \\
\text { (Normal } 1.8-6.3 * 10^{9} / \mathrm{L} \text { ) }\end{array}$ & $3.1(2-4)$ & $3(1.9-3.7)$ & $4.7(3.1-6.5)$ & 0.003 \\
\hline $\begin{array}{l}\text { Platelet count, } 10^{9} / \mathrm{L} \\
\left.\text { (Normal } 125-350^{*} 10^{9} / \mathrm{L}\right)\end{array}$ & $\begin{array}{l}\text { 170.5(138.8- } \\
233.5)\end{array}$ & $180(144.5-242)$ & $134(118-150)$ & 0.006 \\
\hline$<125$ & $14(17.3 \%)$ & $9(13.2 \%)$ & $5(38.5 \%)$ & 0.043 \\
\hline $\begin{array}{l}\text { C reactive protein, mg/L } \\
\text { (Normal 0-6 mg/L) }\end{array}$ & $16.12(6.1-42.8)$ & $13.7(5.6-35.3)$ & $116.7(91.6-126.6)$ & 0.003 \\
\hline$>6$ & $52(67.9 \%)$ & $44(64.7 \%)$ & $8(61.5 \%)$ & 1.000 \\
\hline \multicolumn{5}{|c|}{ Coagulation function (median [ IQR]) } \\
\hline $\begin{array}{l}\text { D-dimer } \\
\text { (Normal 0-0.5ug/ml) }\end{array}$ & $0.15(0.04-0.39)$ & $0.12(0.02-0.34)$ & $0.25(0.22-6.2)$ & 0.026 \\
\hline$>0.5$ & $13(16 \%)$ & $10(14.7 \%)$ & $3(23.1 \%)$ & 0.429 \\
\hline \multicolumn{5}{|c|}{ Blood biochemistry (median [IQR]) } \\
\hline $\begin{array}{l}\text { urea nitrogen, } \mathrm{mmol} / \mathrm{L} \\
\text { (Normal 3.2-7.1 mmol/L) }\end{array}$ & $4(3.2-5.2)$ & $3.9(3.0-5.1)$ & $5.2(4.8-7.4)$ & 0.001 \\
\hline $\begin{array}{l}\text { ALT, IU/L } \\
\text { (Normal 0-40 IU/L) }\end{array}$ & $21(15.8-33)$ & $21(12-33)$ & $23(20-31)$ & 0.306 \\
\hline$>40$ & $17(21 \%)$ & $14(20.6 \%)$ & $3(23.1 \%)$ & 1.000 \\
\hline $\begin{array}{l}\text { AST, IU/L } \\
\text { (Normal 0-40 IU/L) }\end{array}$ & $28(21-42)$ & $25(18.5-34)$ & $42(39-59)$ & 0.001 \\
\hline
\end{tabular}




\begin{tabular}{|c|c|c|c|c|}
\hline & Total $(n=81)$ & survivors $(n=68)$ & $\begin{array}{l}\text { Non-survivors }(\mathrm{n}= \\
13)\end{array}$ & $\begin{array}{l}\mathrm{P} \\
\text { value }\end{array}$ \\
\hline$>40$ & $22(27.2 \%)$ & $13(19.1 \%)$ & $9(69.2 \%)$ & 0.001 \\
\hline $\begin{array}{l}\text { Total protein, } \mathrm{g} / \mathrm{L} \\
\text { (Normal } 60-80 \mathrm{~g} / \mathrm{L} \text { ) }\end{array}$ & $67.8(61.5-71.3)$ & 68.2(63.3-71.7) & $61.6(57-68)$ & 0.056 \\
\hline$<60$ & $14(17.3 \%)$ & $10(14.7 \%)$ & $4(30.8 \%)$ & 0.224 \\
\hline $\begin{array}{l}\text { Albumin, } \mathrm{g} / \mathrm{L} \\
\text { (Normal } 34-54 \mathrm{~g} / \mathrm{L} \text { ) }\end{array}$ & $37.7(33.5-40.7)$ & $38.6(34.9-41)$ & $31.4(30.1-35.9)$ & 0.001 \\
\hline$<34$ & $22(27.2 \%)$ & $14(20.6 \%)$ & $8(61.5 \%)$ & 0.005 \\
\hline $\begin{array}{l}\text { Creatinine, } \mathrm{mmol} / \mathrm{L} \\
\text { (Normal } 50-120 \mathrm{mmol} / \mathrm{L} \text { ) }\end{array}$ & $64(53-78)$ & $64(51.5-77.3)$ & $66(57-80)$ & 0.239 \\
\hline $\begin{array}{l}\text { LDH, IU/L } \\
\text { (Normal 120-250 IU/L) }\end{array}$ & $216(174.5-349)$ & 197(164.8-260) & $463(369-685)$ & $\begin{array}{l}<.001 \\
0.01\end{array}$ \\
\hline$>250$ & $30(37 \%)$ & $18(26.5 \%)$ & $12(92.3 \%)$ & $\hat{0.001}$ \\
\hline $\begin{array}{l}\mathrm{K}, \mathrm{mmol} / \mathrm{L} \\
\text { (Normal 3.5-5.5 mmol/L) }\end{array}$ & $4(3.6-4.3)$ & $4(3.6-4.3)$ & $3.9(3.6-4.1)$ & 0.531 \\
\hline $\begin{array}{l}\mathrm{Na}, \mathrm{mmol} / \mathrm{L} \\
\text { (Normal } 135-145 \mathrm{mmol} / \mathrm{L})\end{array}$ & $140(138-142)$ & $141(139-142)$ & 135(134-136) & $\begin{array}{l}<.001 \\
0.01\end{array}$ \\
\hline \multicolumn{5}{|l|}{ Other indicators (median [IQR]) } \\
\hline $\begin{array}{l}\text { NT-proBNP, pg/ml } \\
\text { (Normal 0-125 pg/ml) }\end{array}$ & 93.3(33-271.3) & $48.9(29.6-158.3)$ & $\begin{array}{l}290.6(161.8- \\
727.8)\end{array}$ & ¿. 001 \\
\hline cTnl (positive) & $9(11.1 \%)$ & $3(4.4 \%)$ & $6(46.2 \%)$ & <. 001 \\
\hline $\begin{array}{l}\text { PCT, ng/ml } \\
\text { (Normal 0-0.05 ng/ml) }\end{array}$ & $\begin{array}{l}0.062(0.042- \\
0.118)\end{array}$ & $\begin{array}{l}0.058(0.038- \\
0.083)\end{array}$ & $\begin{array}{l}0.211(0.102- \\
0.358)\end{array}$ & <. 001 \\
\hline$>0.05$ & $47(58 \%)$ & $34(50 \%)$ & $13(100 \%)$ & 0.001 \\
\hline \multicolumn{5}{|l|}{ Drug treatment } \\
\hline Glucocorticoid & $53(65.4 \%)$ & $41(60.3 \%)$ & $12(92.3 \%)$ & 0.028 \\
\hline Immunoglobulin & 72(88.9\%) & $59(86.8 \%)$ & $13(100 \%)$ & 0.342 \\
\hline \multicolumn{5}{|l|}{ Antiviral drugs } \\
\hline oseltamivir & $62(76.5 \%)$ & $50(73.5 \%)$ & $12(92.3 \%)$ & 0.281 \\
\hline ritonavir & $22(27.2 \%)$ & $16(23.5 \%)$ & $6(46.2 \%)$ & 0.170 \\
\hline lopinavir/ritonavir & $19(23.5 \%)$ & $19(27.9 \%)$ & $0(0 \%)$ & 0.032 \\
\hline
\end{tabular}




\begin{tabular}{|lllll|}
\hline & Total $(\mathrm{n}=81)$ & survivors $(\mathrm{n}=68)$ & $\begin{array}{l}\text { Non-survivors }(\mathrm{n}= \\
13)\end{array}$ & $\begin{array}{l}\mathrm{P} \\
\text { value }\end{array}$ \\
\hline umifenovir & $6(7.4 \%)$ & $6(8.8 \%)$ & $0(0 \%)$ & 0.582 \\
\hline ribavirin & $2(2.4 \%)$ & $2(2.9 \%)$ & $0(0 \%)$ & 1.000 \\
\hline
\end{tabular}

We found that the non-survivors were older than survivors. The incidence of chronic diseases, especially hypertension, diabetes, and coronary heart disease, was also higher among non-survivors. The results showed that the median age of the 13 deceased patients was 69 years (IQR, 60-79 years); of these 11 $(84.6 \%)$ were older than 60 years, and the majority was male (61.5\%). In contrast, the median age of survivors was 42 years (IQR, 33-54 years). There were also several differences in the laboratory findings between survivors and non-survivors. The median lymphocyte count of survivors was $1 * 10^{9} / \mathrm{L}(\mathrm{IQR}, 0.7-$ $1.4^{\star} 10^{9} / \mathrm{L}$ ), while the median lymphocyte count of non-survivors was $0.5^{\star} 10^{9} / \mathrm{L}$ (IQR, $0.3-0.8^{\star} 10^{9} / \mathrm{L}$ ). The lymphocyte count was lower than normal in 36 (52.9\%) survivors and in 12 (92.3\%) non-survivors (Table 1 and Fig. 2). The median urea nitrogen level was lower in survivors than non-survivors (3.9 mmol/L [IQR, 3.0-5.1 mmol/L] vs. $5.2 \mathrm{mmol} / \mathrm{L}$ [IQR, 4.8-7.4 mmol/L], respectively). The aspartate aminotransferase level was lower in survivors than non-survivors (25 IU/L [IQR, 18.5-34 IU/L] vs. 42 IU/L [IQR, 39-59 IU/L], respectively). The lactate dehydrogenase level was lower in survivors than nonsurvivors (197 IU/L [IQR, 164.8-260 IU/L] vs. 463 IU/L [IQR, 369-685 IU/L], respectively) (Table 1 and Fig. 3). Most patients in both groups received antibacterial (moxifloxacin, cefoperazone sodium and sulbactam sodium, azithromycin, and cephalosporin) and antiviral therapy (oseltamivir, ritonavir, lopinavir/ritonavir, and umifenovir); only the $\mathrm{p}$-value for lopinavir/ritonavir differed. Moreover, intravenous immunoglobulin was used in most patients (88.9\%) (all data shown in Table 1).

Our results revealed significant differences between medical staff members and non-medical individuals in the time from onset to admission(Figure 4), comorbidity, disease classification, and prognosis. The median time for medical staff members from onset to admission or medication was 3.5 days (IQR, 2-5 days), while that for non-medical individuals was 7 days (IQR, 4.5-10 days). Moreover, medical staff members had fewer comorbidities. Most medical staff members (86.8\%) were diagnosed with common pneumonia, while most non-medical individuals (41.9\%) were diagnosed with critical pneumonia. All of the medical staff members were cured, while $13(30.2 \%)$ of the non-medical individuals died (all the data is in Table 2). 
Table 2

Time from onset to admission, disease classification, and prognosis of patients with 2019-nCoV pneumonia. Data are median (IQR), $\mathrm{n}(\%)$, or $\mathrm{n} / \mathrm{N}(\%)$, where $\mathrm{N}$ is the total number of patients with available data. $p$ values comparing medical staff and non-medical staff are from $\chi^{2}$ test, Fisher's exact test, or Mann-Whitney U test.

\begin{tabular}{|c|c|c|c|c|}
\hline & $\begin{array}{l}\text { Total }(n= \\
81)\end{array}$ & $\begin{array}{l}\text { Medical staff( }(n= \\
38)\end{array}$ & $\begin{array}{l}\text { Non-medical staff( } n= \\
\text { 43) }\end{array}$ & $\begin{array}{l}P \\
\text { value }\end{array}$ \\
\hline Age(median [IQR], y) & $49(35-59)$ & $36(30-43)$ & $57(51-71)$ & $\hat{0.001}$ \\
\hline Sex & 吅 & 吅 & प्रा & 0.142 \\
\hline Male & $39(48.1 \%)$ & $15(39.5 \%)$ & $24(55.8 \%)$ & प्रा \\
\hline Female & $42(51.9 \%)$ & $23(60.5 \%)$ & $19(44.2 \%)$ & 吅 \\
\hline $\begin{array}{l}\text { Time from onset to CT } \\
\text { positive } \\
\text { (median [IQR], d) }\end{array}$ & $4(2-8)$ & $2.5(1-4)$ & $6(3.5-9)$ & $\dot{0} 001$ \\
\hline $\begin{array}{l}\text { Time from onset to } \\
\text { admission } \\
\text { (median [IQR], d) }\end{array}$ & $5(3-9)$ & $3.5(2-5)$ & $7(4.5-10)$ & $\dot{0} 001$ \\
\hline $\begin{array}{l}\text { Time from onset to } \\
\text { medication } \\
\text { (median [IQR], d) }\end{array}$ & $5(3-9)$ & $3.5(2-5)$ & $7(4.5-10)$ & $\dot{0} 001$ \\
\hline Comorbidity & $38(46.9 \%)$ & $12(31.6 \%)$ & $26(60.5 \%)$ & 0.009 \\
\hline hypertension & $16(19.8 \%)$ & $1(2.6 \%)$ & $15(34.9 \%)$ & $\hat{0.001}$ \\
\hline diabetes & $6(7.4 \%)$ & $0(0 \%)$ & $6(14 \%)$ & 0.027 \\
\hline Coronary heart disease & $7(8.6 \%)$ & $0(0 \%)$ & $7(16.3 \%)$ & 0.013 \\
\hline Tumor & $3(3.7 \%)$ & $0(0 \%)$ & $3(7 \%)$ & 0.244 \\
\hline COPD & $3(3.7 \%)$ & $0(0 \%)$ & $3(7 \%)$ & 0.244 \\
\hline Other & $25(30.9 \%)$ & $11(28.9 \%)$ & $14(32.6 \%)$ & 0.726 \\
\hline \multicolumn{5}{|l|}{ Classification } \\
\hline Commom & $45(55.6 \%)$ & $33(86.8 \%)$ & $12(27.9 \%)$ & $\dot{0.001}$ \\
\hline Severe & $17(21 \%)$ & $4(44.7 \%)$ & $13(30.2 \%)$ & $\dot{0} 001$ \\
\hline Critical & $19(23.4 \%)$ & $1(2.6 \%)$ & $18(41.9 \%)$ & $\hat{0} .001$ \\
\hline
\end{tabular}




\begin{tabular}{|lllll|}
\hline & $\begin{array}{l}\text { Total }(\mathrm{n}= \\
81)\end{array}$ & $\begin{array}{l}\text { Medical staff( } \mathrm{n}= \\
38)\end{array}$ & $\begin{array}{l}\text { Non-medical staff( } \mathrm{n}= \\
43)\end{array}$ & $\begin{array}{l}\mathrm{P} \\
\text { value }\end{array}$ \\
\hline Prognosis & & & & \\
\hline Cured & $63(77.8 \%)$ & $38(100 \%)$ & $25(58.1 \%)$ & 0.001 \\
\hline Die & $13(16 \%)$ & $0(0 \%)$ & $13(30.2 \%)$ & 0.001 \\
\hline In hospital & $5(6.2 \%)$ & $0(0 \%)$ & $5(11.6 \%)$ & 0.001 \\
\hline
\end{tabular}

\section{Discussion}

In this descriptive study, we report the clinical features of 81 patients with laboratory-confirmed 2019nCoV infection at Hankou Hospital in Wuhan, China. We examined the epidemiological, demographic, clinical, laboratory, radiological, treatment, and prognosis factors of survivors and non-survivors and of medical staff members and non-medical individuals.

We compared the medical records and laboratory data of survivors and non-survivors. The median age of non-survivors was 69 , which was 27 years older than that of survivors. Old age can be considered a risk factor for death, as reported elsewhere [4]. The mortality rate was higher in patients with hypertension, diabetes, coronary heart disease, or a combination of these. Studies have shown that poor glycemic control has an important effect on infection-related mortality [5] and may be associated with impaired immune function in diabetic patients [6, 7]; there is evidence that better glycemic control improves immune mechanisms and reduces susceptibility and severity of infection [8,9]. Most of the included patients were admitted with a fever and cough; some also had fatigue and dyspnea. There were no statistically significant differences between survivors and non-survivors in the first symptoms or in the course of disease before admission. Lymphocytes decreased significantly in all of the 2019-nCoV patients, and there were fewer lymphocytes in non-survivors than in survivors, which is similar to previous reports $[10,11]$. The increase of C-reactive protein, lactate dehydrogenase, D-dimer, and procalcitonin showed a similar trend; the values of non-survivors were higher. These markers are also risk factors for prognosis.

In terms of treatment, different kinds of antiviral drugs were consumed before admission and in mild illness. Supportive glucocorticoid and immunoglobulin treatments were used for most patients, and there was no significant difference in treatment between those who died and those who were cured. Despite the various treatments available, 13 patients died; the median time from admission to death was 15 days (IQR, 11-21 days), and the chest CT scans showed rapid deterioration (Fig. 5).

In this study, more than $80 \%$ of the medical staff members were diagnosed with common pneumonia, and $100 \%$ of them were cured and discharged from hospital. In contrast, $30 \%$ of non-medical individuals 
died. Medical staff were most likely infected with the virus due to close contact with patients and inadequate protective measures. Two non-medical individuals were infected by relatives; others had no clear history of contact. When comparing the age, time from onset to admission, and comorbidity, the figures for the medical staff members were smaller than those of the non-medical individuals. Most of the medical staff members were quadragenarians; as such, they had a better physical basis and better understanding of the disease. It may have been easier for them to detect the symptoms and diagnose themselves, which could explain the above statistical results. The medical staff members' high compliance, that is, high rate of following the doctor's advice, attaching great importance to the disease, and positive attitude toward supportive treatments such as glucocorticoid and gamma globulin are important factors that may have influenced their positive outcomes. Female health-care workers accounted for $60 \%$ of the medical patients in this study. This is reflective of the fact that female healthcare workers are the main force in the fight against this epidemic in Wuhan. Women account for more than $50 \%$ of doctors and more than $90 \%$ of nurses in the area [12]. Due to the widespread and drastic effect this outbreak has had on society, psychotherapy is an important in addition to standardized and effective drug treatment. Research in this area is already underway [13].

This study had several limitations. First, only 81 patients were included. There were potential biases and residual confounding in this small-sample observational study, and the results should be interpreted with caution. Second, the therapeutic efficacies and the varying effects of different antiviral drugs could not be reflected in this study.

Above are the main points of our study.

\section{Conclusion}

Our study was different from previous studies because of the comparison between medical staff members and non-medical staff individuals. Medical staff members are the main force in the fight against the epidemic of 2019-nCoV, they had better prognoses due to timely detection and treatment, young age, fewer comorbidities, and better medical compliance. Only when the medical staff members pay more attention to themselves and do a good job of protection, can it be more conducive to the treatment of patients with 2019-nCoV pneumonia and the prevention and control of 2019-nCoV.

Previous cardiovascular disease or diabetes, and advanced age, were potential risk factors for death. And some important blood test indicators like PCT, LDH, Leukomonocyte count, C-reactive protein, D-dimer, Urea nitrogen, and AST had statistical difference between survivors and non-survivors, as well as other indicators like Platelet count, Albumin, NT-proBNP, and CTnI. These results are similar to previous studies, which can provide a basis for possible trends in disease.

In summary, fewer comorbidities, timely medical treatment and compliance with the doctor's instructions are helpful to the recovery of the disease to a large extent. Significant changes in some laboratory markers may indicate a poor prognosis. More related studies are needed in the future. We hope that our findings will provide a scientific basis for further prevention and treatment of 2019-nCoV pneumonia. 


\section{Abbreviations}

2019-nCoV: 2019 novel coronavirus; AST: aspartate aminotransferase; ALT: alamine aminotransferase; LDH: lactate dehydrogenase; PCT: procalcitonin; NT-proBNP: N-Terminal pro-brain natriuretic peptide; CTnl: Cardiac troponin I; CT: computed tomography; ICU: Intensive care unit; IQR: Interquartile ranges; SPSS: Statistical product and service solutions.

\section{Declarations}

Ethics approval and consent to participate: This study is approved by the ethics committees of Hankou Hospital (HKYY-2020-022) and Changzheng Hospital (2020SL009), and written informed consent was obtained from all of the patients or their next of kin. And we also get the consent of the family of the deceased to publish the computed tomography image.

Availability of data and materials: All data generated or analysed during this study are included in this published article.

Funding: This work was supported by the National Natural Science Foundation (grants 81670015 and 81370137 to Prof. Tang).

Competing interests: The authors declare that they have no competing interests.

\section{Authors' contributions and consent for publication}

HJX, LY and XY designed the study and undertook most of the work, they should be regarded as co-first author. MYS and WW participated in data collection and analysis. TH and LWQ are the corresponding authors. All authors read and approved the final manuscript.

Acknowledgements: Not applicable.

\section{References}

1. D. S. Hui et al., The continuing 2019-nCoV epidemic threat of novel coronaviruses to global health The latest 2019 novel coronavirus outbreak in Wuhan, China. Int J Infect Dis 91, 264-266 (2020).

2. H. Lu, C. W. Stratton, Y.-W. Tang, Outbreak of pneumonia of unknown etiology in Wuhan, China: The mystery and the miracle. J Med Viro/ 92, 401-402 (2020).

3. C. Huang et al., Clinical features of patients infected with 2019 novel coronavirus in Wuhan, China. Lancet (London, England) 395, 497-506 (2020).

4. C. Wu et al., Risk Factors Associated With Acute Respiratory Distress Syndrome and Death in Patients With Coronavirus Disease 2019 Pneumonia in Wuhan, China. JAMA Intern Med, 10.1001/jamainternmed.2020.0994 (2020). 
5. Y. Hirata et al., Association of hyperglycemia on admission and during hospitalization with mortality in diabetic patients admitted for pneumonia. Intern Med 52, 2431-2438 (2013).

6. J. D. Bagdade, R. K. Root, R. J. Bulger, Impaired leukocyte function in patients with poorly controlled diabetes. Diabetes 23, 9-15 (1974).

7. C. M. Nolan, H. N. Beaty, J. D. Bagdade, Further characterization of the impaired bactericidal function of granulocytes in patients with poorly controlled diabetes. Diabetes $\mathbf{2 7}, 889-894$ (1978).

8. S. J. Gallacher et al., Neutrophil bactericidal function in diabetes mellitus: evidence for association with blood glucose control. Diabet Med 12, 916-920 (1995).

9. D. Ardigo, S. Valtuena, I. Zavaroni, M. C. Baroni, R. Delsignore, Pulmonary complications in diabetes mellitus: the role of glycemic control. Curr Drug Targets Inflamm Allergy 3, 455-458 (2004).

10. W.-J. Guan et al., Clinical Characteristics of Coronavirus Disease 2019 in China. N Engl J Med, 10.1056/NEJMoa2002032 (2020).

11. N. Chen et al., Epidemiological and clinical characteristics of 99 cases of 2019 novel coronavirus pneumonia in Wuhan, China: a descriptive study. Lancet (London, England) 395, 507-513 (2020).

12. http://www.cnr.cn/shanghai/tt/20200308/t20200308_525008064.shtml.

13. X. Jiang et al., Psychological crisis intervention during the outbreak period of new coronavirus pneumonia from experience in Shanghai. Psychiatry Res 286, 112903-112903 (2020).

\section{Figures}


Independent-Samples Mann-Whitney U Test

\section{Group}

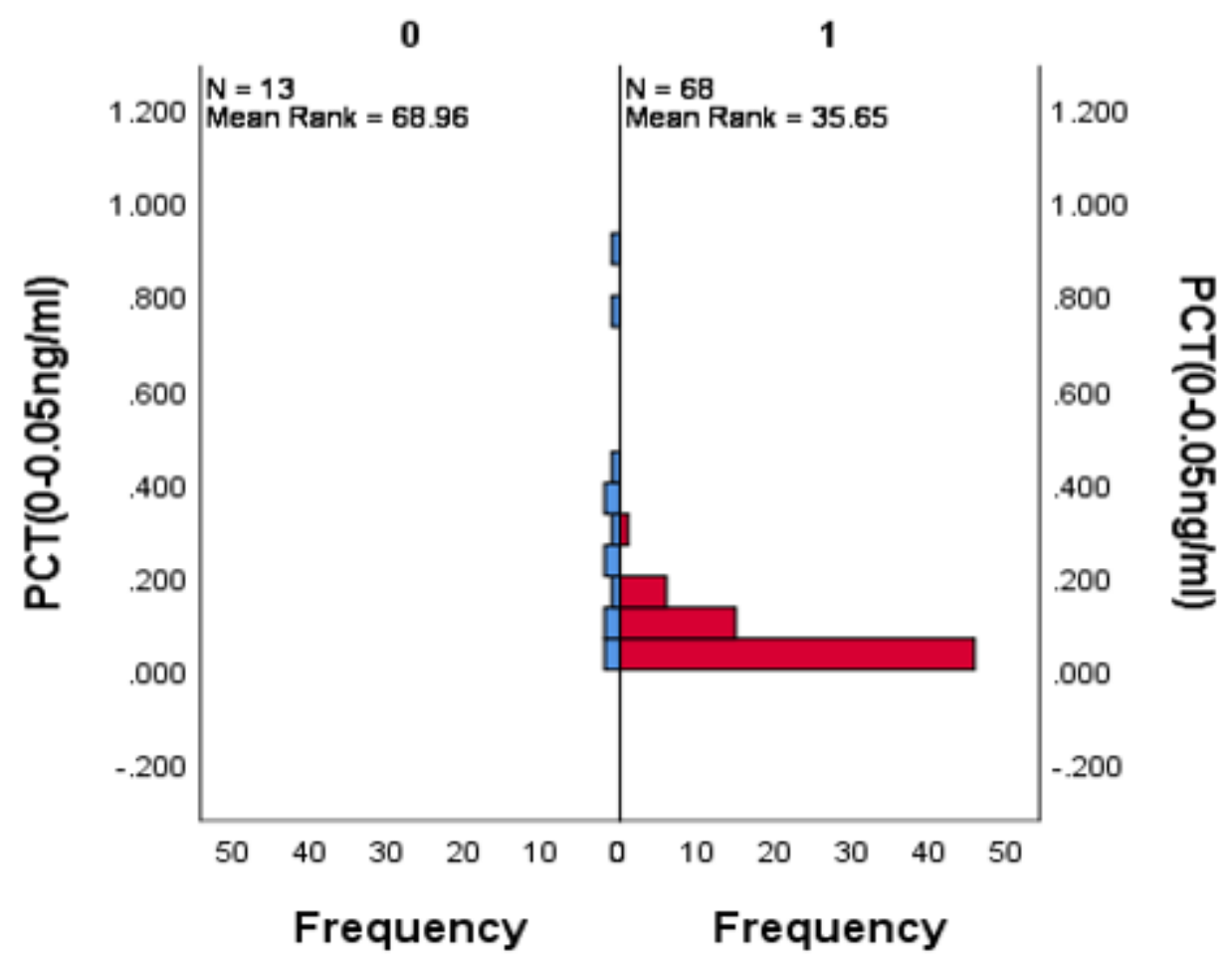

Figure 1

Comparison between non-survivors and survivors in PCT. 


\section{Independent-Samples Mann-Whitney U Test \\ Group}

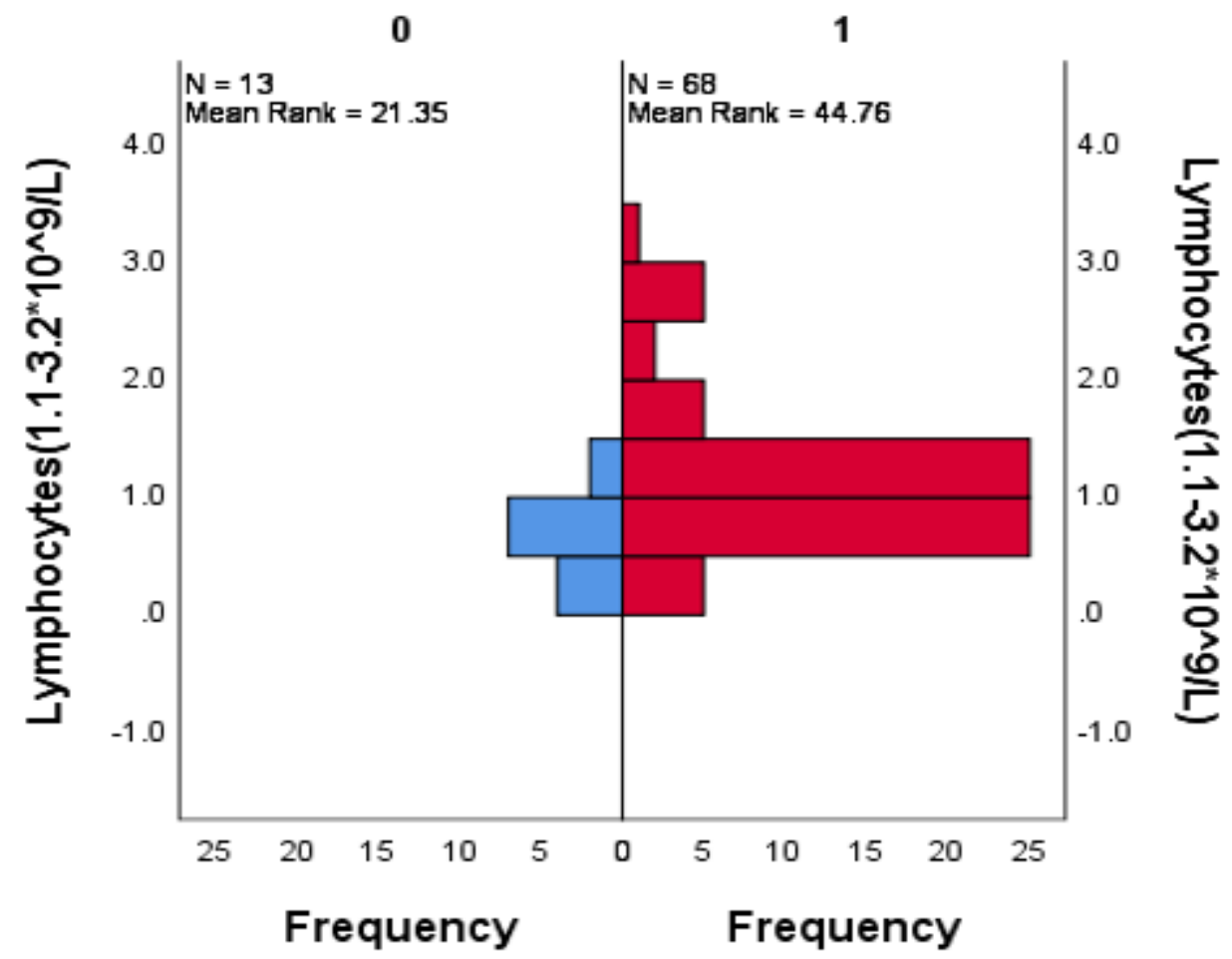

Figure 2

Comparison between non-survivors and survivors in Lymphocytes count. 
Independent-Samples Mann-Whitney U Test

\section{Group}

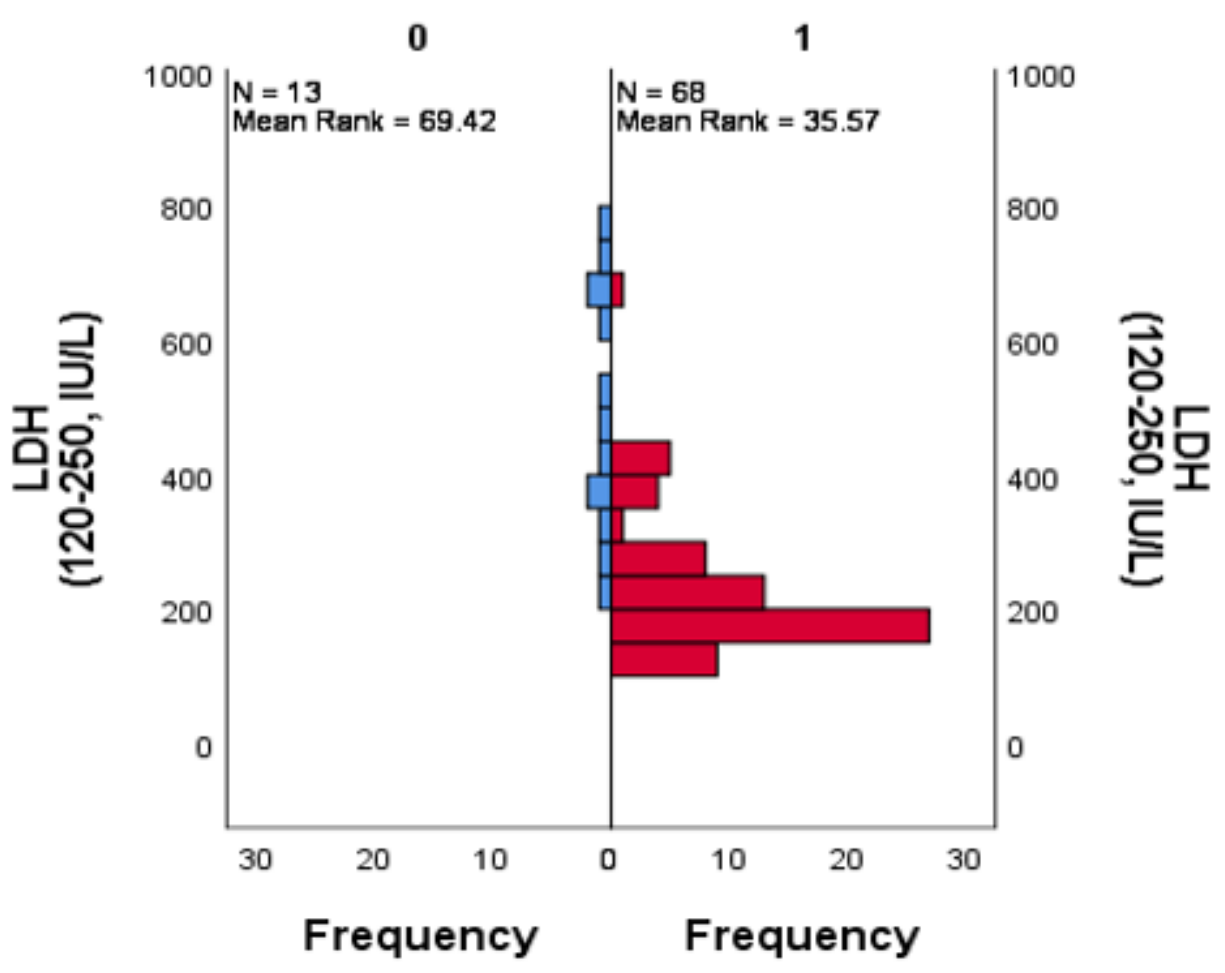

Figure 3

Comparison between non-survivors and survivors in LDH. 
Independent-Samples Mann-Whitney U Test

work

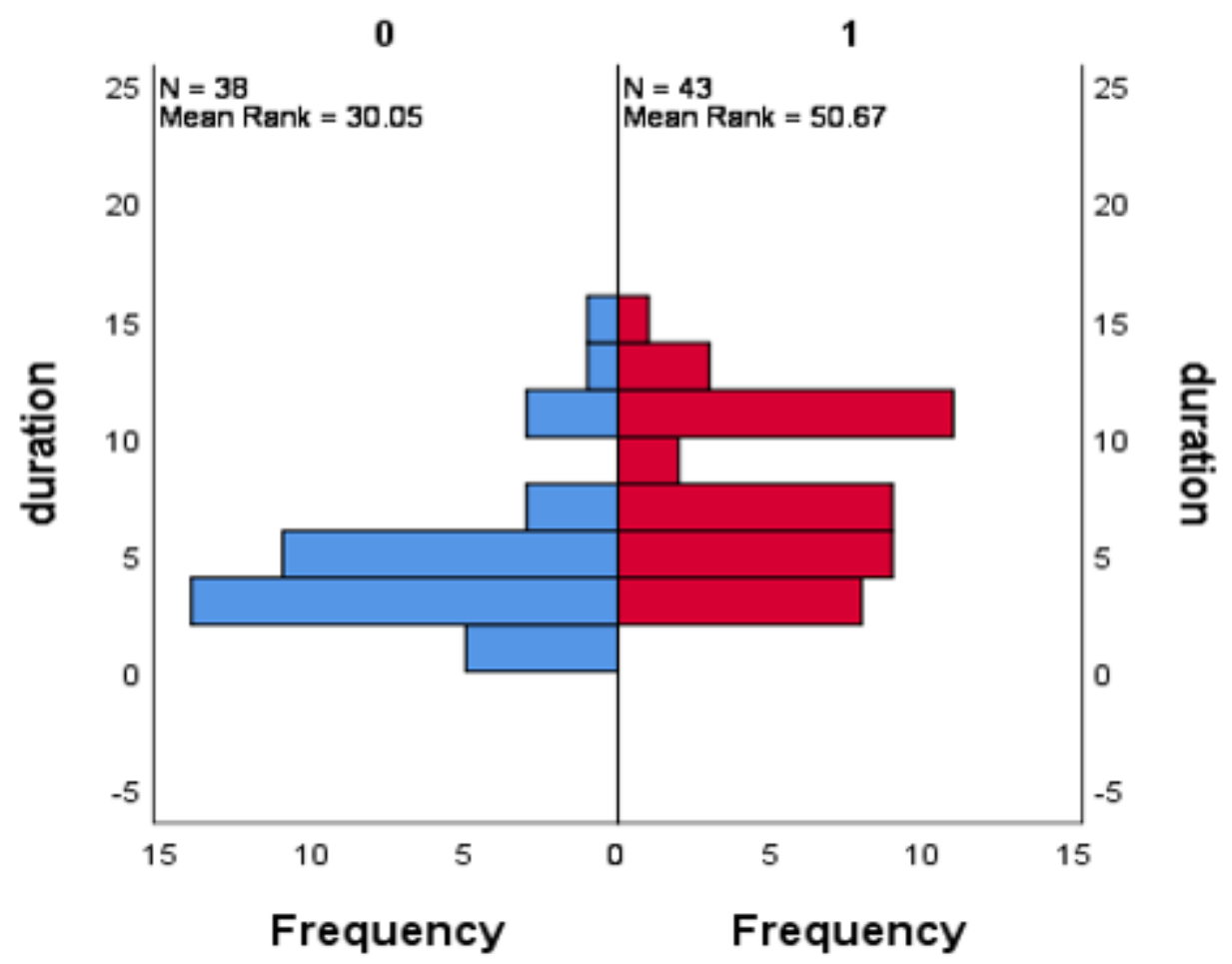

Figure 4

Comparison between medical staff and non-medical staff in the time from onset to admission or medication. 
Fig 5.1 Computed tomography images on day 7 after symptom onset
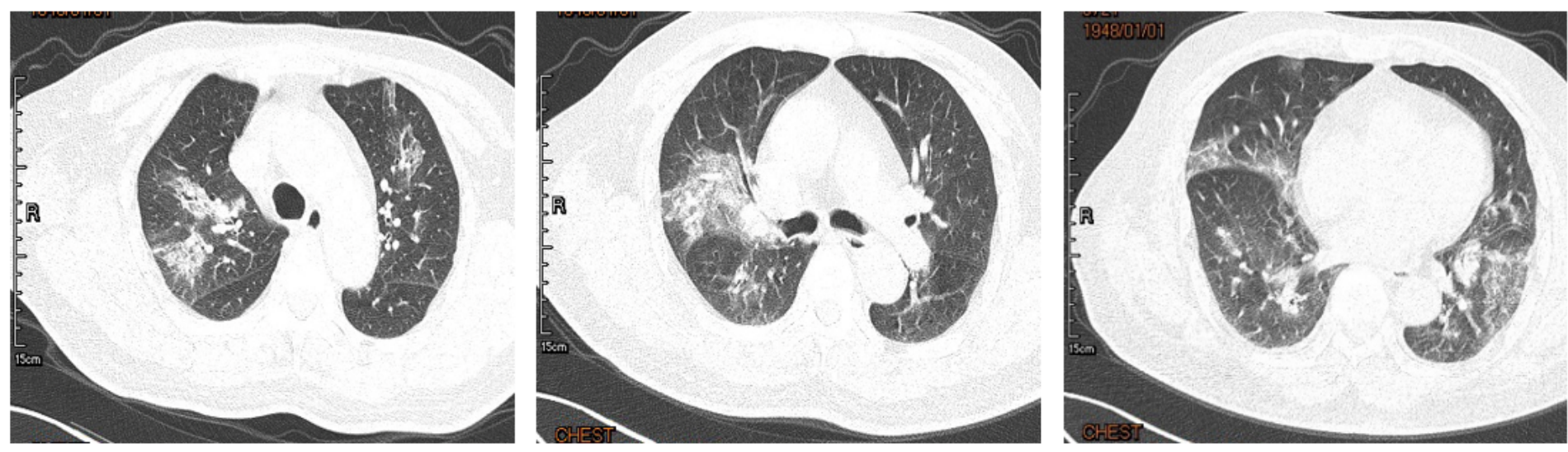

Fig 5.2 Computed tomography images on day 10 after symptom onset
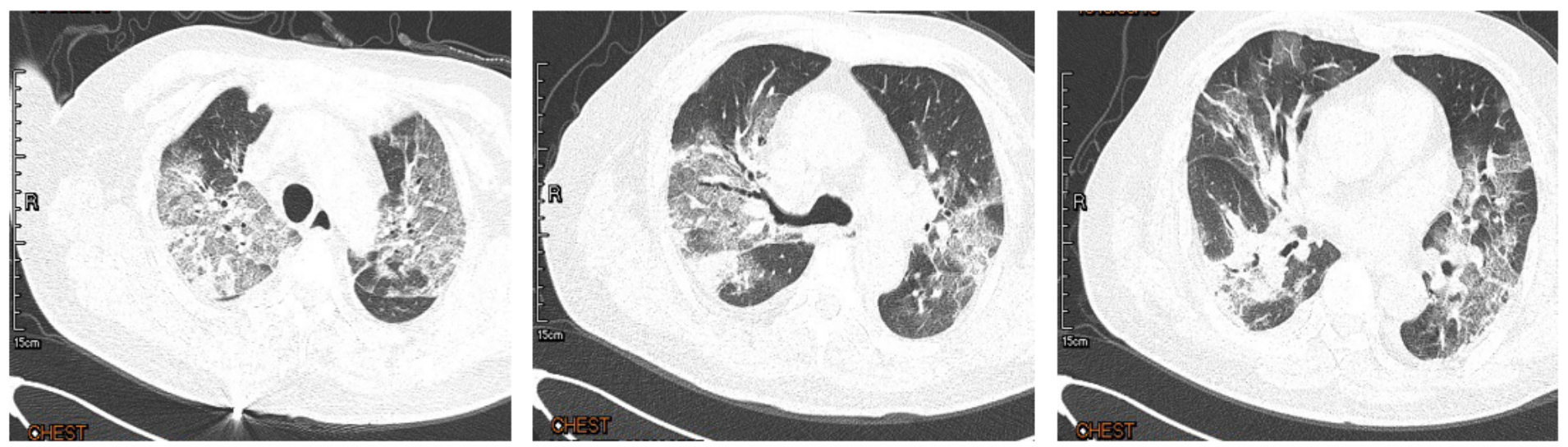

Figure 5

Chest Computed Tomographic Images of a 72-Year-Old non-survivor Infected With 2019-nCoV. Fig 5.1 Computed tomography images obtained on January 8, 2020, show ground glass opacity in both lungs on day 7 after symptom onset. Fig 5.2 Computed tomography images obtained on January 11, 2020, show the change in lungs aggravates on day 10 after symptom onset, and he died on day 22 after symptom onset. 